\title{
Young People Caring for Their Parents: A Collaborative Study in Japan and Sri Lanka
}

\author{
Koichi Yaguchi ${ }^{1, *}$, Varathagowry Vasudevan ${ }^{2}, K_{0 h}$ Miyanaga ${ }^{1}$, Mika Tanaka ${ }^{3}$, Fumiko Mega ${ }^{1}$, \\ Osamu Kobayashi ${ }^{1}$, Chiyoko Kodama ${ }^{4}$, Masaaki Abe ${ }^{1}$, Kazue Kanno ${ }^{1}$, Tomoko Kutsuzawa ${ }^{4}$, \\ Riddley Jayasinghe ${ }^{5}$, Kaluvila M. Y. Karunaratna ${ }^{5}$, Wijesinghe M. Danapala ${ }^{6}$, Jeyaruban V. R. ${ }^{5}$ \\ ${ }^{1}$ Department of Social Work, School of Health Sciences, Tokai University, Japan \\ ${ }^{2}$ Department of Social Work, Director of Social Work, National Institute of Social Development Sri Lanka, Sri Lanka \\ ${ }^{3}$ Department of Nursing, Kitasato University, Japan \\ ${ }^{4}$ Department of Nursing, School of Health Sciences, Tokai University, Japan \\ ${ }^{5}$ Department of Social Work, National Institute of Social Development (Ministry of Social Services) Sri Lanka, Sri Lanka \\ ${ }^{6}$ Department of Criminology and Criminal Justice, University of Sri Jayewardenapura, Sri Lanka
}

\begin{abstract}
Population aging is a global problem, but its magnitude and manifestation vary across countries. Japan faces the challenge of a super-aged society, whereas Sri Lanka is experiencing rapid demographic transition: a problem in the Asia Pacific region that needs urgent attention. The degree to which young adults provide support for aging parents depends on their awareness/consciousness of older adults, and differs according to social images that influence intergenerational relationships. This quantitative study investigated young adults' opinions and perceptions toward their aging parents and intergenerational activities, and explored their care consciousness and anticipated challenges. Representative samples of 1064 university students from Japan and 600 students from Sri Lanka (aged 20-22 years) completed a self-administered questionnaire. Students who had an attitude of discrimination toward older people also perceived older adults as having a significant amount of experience and knowledge. They believed in traditional forms of caregiving with social support and appeared to have developed values to prepare themselves to face the challenges of population aging. Overall, female students were more concerned about population aging than male students. However, with the aging population increasing, opinions and social values about older adults face dramatic social challenges, despite maintenance of cultural and religious traditions.
\end{abstract}

Keywords Consciousness, Attitudes, Aging Society, Frail Aged, University Students

\section{Introduction}

Old age sees the onset of many physiological, psychological, and adjustment problems among older adults. Conflicts among generations may arise as a result of these problems. Successful care for aging people requires the fulfillment of older adults' physical, social, psychological, spiritual, and economical needs and often indicates improved quality of life resulting in decreased morbidity and mortality. This study focused on perceptions and opinions university students (aged 20-22 years) hold relating to their aging parents, and represents collaboration between Japan and Sri Lanka. Japan previously experienced a rapid rate of population aging from $7.0 \%$ in 1970 to $14.0 \%$ in 1994 (Ministry of Internal Affairs and Communications, 2016). However, Sri Lanka is experiencing population aging in a context of lower incomes and less economic development than what has occurred in countries such as Japan. Although most developing countries continue to have younger populations, Sri Lanka remains an exception (Institute for Health Metrics and Evaluation, Sri Lanka, 2015).

\section{Demographic Transition and Aging in Japan and Sri Lanka}

Of the 127 million people in Japan, 32\% are considered to be aging, with Japan ranking first in the world in terms of the percentage of the aging population. Sri Lanka's aging population represents $12.5 \%$ of 20 million people, and is ranked 71 (DESA; Economic and Social Affairs of the United Nations Secretariat, 2013). Population aging denotes a shift in the distribution of a country's population toward the older ages. The steady increase in the number of older people impacts the foundation of society, meaning that aging has sociological and psychological impacts as well as being a biological phenomenon. Although aging is 
a global problem, its magnitude and manifestation differ across countries. For example, Japan faces the challenge of a super-aged society, whereas Sri Lanka is expecting a rapid increase in population aging in the context of rapid demographic transition. This means that all indicators of the aging process are progressing upwards at a much faster rate than experienced in other Asia Pacific countries.

In many developing countries, a rapid increase in international labor migration among working-age young adults has reduced the proportion of the working-age population and increased the proportion of older adults (Silva, 2014). The proportion of the Sri Lankan population aged 60 years and over increased by nearly $3.3 \%$ in 10 years, from $9.2 \%$ in 2001 to $12.5 \%$ in 2011 . By 2041, 24.8\% of the Sri Lankan population is predicted to be aged 60 years or above. Between 2010 and 2041, a moderate increase in the Sri Lankan population from 20 to 22 million is expected (about $9 \%$ ), but the older population ( $\geq 60$ years) is expected to increase by 2.8 million (from 2.5 million in 2010 to 5.3 million in 2041); an increase of over $100 \%$ or a doubling of the older adult population. Sri Lanka can therefore expect to have one of the largest aged populations in the Asia Pacific region by 2020. This may be partly attributed to development of welfare services, especially universal free health and educational services, that helped reduce the mortality rate and increase life expectancy in Sri Lanka (DESA, 2013). In Japan, 2014 estimates indicated that $33.0 \%$ of the population was aged over $>60$ years, $25.9 \%$ was aged $\geq 65$ years, and $12.5 \%$ was aged $\geq 75$ years. People aged $\geq 65$ years make up one-fifth of the total Japanese population, this estimated to reach one-third by 2050 (United Nations Population Division, 2013).

\section{Elder Care}

In traditional Japanese and Sri Lankan cultures, caring for older adults is the sole responsibility of their children. Increased female labor force participation, increased consumer needs, lowering of family incomes, migration to cities and foreign countries (especially in Sri Lanka) have broken down traditions of the extended family system, leaving older adults increasingly vulnerable. However, older adults are valuable repositories of tradition, experience, and wisdom, which if used productively, may influence socioeconomic development and mitigate the negative effects of rapid population aging (Silva, 2014). Traditionally, the care of older people is the concern and responsibility of the family, with older adults considered a blessing to the family. However, the role and status of older adults have weakened as society has changed. In industrialized countries such as Japan and Korea and developing countries such as Sri Lanka, caring for older people has become a serious problem for family caregivers, particularly in the context of increasing poverty, high costs of living, expensive medical treatment, loneliness, and lack of companionship.
Older adults are often viewed as inflexible in thought, and considered weak, sick, slow, and childlike (Prakash, 2003). In addition, older adults may feel that they have no role to play, and perceive themselves as a burden to their family, powerless, ignored, unable to contribute in any way, and sometimes an annoyance to younger generations (Prakash, 2003). Attitudes, beliefs, dress, speech, and style are important indicators of old age (Desai \& Raju, 2000). Traditionally, older adults in Japan and Sri Lanka were assigned a place of honor and respect, as exemplified by social values and norms, and religious texts and writings referring to children as the caregivers of elderly parents (Cabinet Office, Government of Japan, 2003); United Nations Population Fund and Population Association of Sri Lanka, 2004).

\section{Consciousness on 'Aging' among University Students}

The awareness or consciousness of aging is significant in building intergenerational relationships, and varies among young adults according to the social perceptions they develop about aging. Older adults are often considered resources and repositories of experiences. However, university students also demonstrate negative perceptions and attitudes that influence their relationships with older adults. A society with healthy older adults is likely to be a healthy society in which the knowledge and experiences of older adults can benefit future generations (Somasundaram \& Sivayokan, 2005). Bowen and Skirbek (2013) noted that "older people were perceived as more competent in countries where they participated in paid or volunteer work, were independent in life, possessed average education, with equal representation of the genders, with average cognitive abilities" (Bowen \& Skirbek, 2013, p. 974). Young adults may develop positive or negative perceptions of older adults, and social perceptions and opportunities are significant factors in building intergenerational relationships and older adult care.

Ageism, defined as negative stereotypes about people of different ages, is common among younger adults and affects relationship building across generations. Merge (2006) found nursing students had negative attitudes toward older adults, with students' personal beliefs, values, culture, experience or observations, and perceptions toward elder care making it difficult to recruit nurses in geriatric nursing. Moreover, Koh (2012) reported that students often perceive caring for older people as an unattractive option; a perception that has considerable influence on their future professional practice. That author noted that "if students are provided with the relevant preparatory advice and support, they may engage in enriched learning experiences, to deliver quality care and develop positive attitudes in caring for older people in their professional practice" (Koh, 2012, p. 16). Reasons cited for the lack of interest in working with older people included poor experiences of providing care for older people, inability to relate to or communicate with older people, and 
a perception that such work is depressing and boring (Koh, 2012). The association between aging and disability underpins these negative perceptions of working with older people. When the survey was repeated after graduation, students demonstrated more positive attitudes toward older people and were less likely to express stereotypical attitudes towards aging, suggesting that positive exposure to older people can challenge ageist views (Henderson, Xiao, Siegloff, Kelton, \& Peterson, 2008) These previous studies clarified that students' social perceptions may change following direct experiences and opportunities to work with older adults. Therefore, the present study did not focus on students who had experience of working with older adults.

This collaborative study was undertaken by researchers in Japan and Sri Lanka with the goal of investigating and supporting intergenerational relationship building in the Asia Pacific region. This study adhered to the methods described in the research plan submitted to the relevant university in Japan to ensure that comparisons were meaningful. Therefore, in both Japan and Sri Lanka, the same methods were used to explore and compare university students' perceptions and opinions toward their aging parents.

\section{Objectives}

Based on the social context in Japan and Sri Lanka, this study aimed to:

- ascertain university students' opinions and perceptions towards their role in terms of their aging parents;

- $\quad$ explore university students' care consciousness and expected challenges; and

- Identify interest in intergenerational activities.

\section{Materials and Methods}

This study used quantitative research methodology. A stratified random sample of 1064 students was drawn from two states and four private universities in urban areas near Tokyo, Japan. A sample of 600 students was recruited from four national universities located near Colombo city in Sri Lanka (based on faculty, age, sex, and university). The criteria for sampling were almost the same in both countries: urban areas, $50 \%$ of each sex, junior or senior university grades, and the number of respondents in relation to the total population (Japan: Sri Lanka $=2: 1$ ). Participants in both samples were aged 20-22 years, with a mean age of 20.2 years in Japanese students and 21.3 years in Sri Lankan students. There were 368 (35\%) male students from Japan plus 229 (38.2\%) male students from Sri Lanka, and 696 (65\%) female students from Japan plus $371(61.8 \%)$ female students from Sri Lanka. This study aimed to include young adults who were about to take up the challenge of caring for aging parents, ascertain their perceptions and opinions about their parents and the caregiving role that they would take up in future.

\section{Data Collection}

A questionnaire was constructed and pre-tested to investigate students' attitudes toward older adults, opinions about their duty to support their parents, and their degree of interest in population aging. There were 26 general questions covering: participants' family backgrounds; experience of living with aging grandparents; preferences about living with parents before and after marriage; views on economic support, primary responsibility for elder care, and nursing homes; opinions on the traditional form of caregiving and its sustainability; the meaning of "being good" to their parents; interest about the issue of aging; expectations of government; images of older adults, their current situation, and discrimination or prejudice; and awareness of intergenerational activities (Cabinet Office, Government of Japan, 2003; Hosaka \& Sodei, 1988). As the effectiveness of the image scale for the aged was confirmed using Japanese students (Hosaka \& Sodei, 1988), we only analyzed image scale results for Japanese students. The scale comprised 36 paired-adjective lists, each with seven points. Six factors were extracted using factor analysis with varimax rotation: social extroversion, competence, active independence, happiness, cooperativeness, and mildness/gentleness. A total of three points for each factor, calculated from the three paired-adjective items from the highest to third-highest factor loadings, were identified as the factor scores. Items covering perceptions of older adults were originally selected and listed from the perspective of ageism (Palmore, 2000). In this study, items concerning discrimination or prejudice of the aged were divided into Facts on Aging Quiz-positive (FAQ-positive) and Facts on Aging Quiz-negative (FAQ-negative). After pre-testing and obtaining ethical permission and participants' informed consent, the self-administered questionnaire was distributed to participants. Completed questionnaires were scrutinized before data entry. Data was then encoded, entered into a personal computer, and analyzed by members of the research team from the Department of Social Work, Tokai University, Japan, and the School of Social Work of the National Institute of Social Development (NISD), Sri Lanka.

\section{Ethical Considerations}

This study was implemented by the Council of Tokai University in 2014 based on the ethical guidelines compiled by the Japanese Society for the Study of Social Welfare, the research implementation plan, and on ethical clearance granted by the Council Subcommittee on Research and Ethics of the NISD in Sri Lanka (2014). 


\section{Data Analysis}

After completion of data collection, all questionnaires were scrutinized and approved for encoding and data entry. Data was analyzed using IBM SPSS Statistics for Windows, Version 21 (IBM Corp., Armonk, NY, USA). Next, the data was tabulated and inferences drawn using statistical tests. Chi-square tests (p-values) were used to examine students' attitudes toward older adults and the degree of correlation among males and females. The degree to which students' primary attributes affected their attitudes toward older adults and the duty to support their parents, and the degree of interest in population aging were also analyzed.

\section{Results}

This study examined factors that influenced students' consciousness about supporting their aging parents, their perceptions of older adults, and their level of concern about population aging. Findings derived from data gathered in both countries are presented below.

Table 1. Details of Participants' Family Members

\begin{tabular}{|c|c|c|c|c|c|c|c|c|c|c|}
\hline \multirow{3}{*}{ Family members } & \multicolumn{4}{|c|}{ Japan(1) } & \multicolumn{4}{|c|}{ Sri Lanka(2) } & \multirow{3}{*}{$\begin{array}{c}\chi^{2} \text { test } \\
\text { (1) vs.(2) }\end{array}$} & \multirow{3}{*}{ Probability } \\
\hline & \multicolumn{2}{|c|}{ Yes } & \multicolumn{2}{|c|}{ No } & \multicolumn{2}{|c|}{ Yes } & \multicolumn{2}{|c|}{ No } & & \\
\hline & $\mathbf{N}$ & $\%$ & $\mathbf{N}$ & $\%$ & $\mathbf{N}$ & $\%$ & $\mathbf{N}$ & $\%$ & & \\
\hline Father(alive) & 1041 & 97.8 & 23 & 2.2 & 552 & 92 & 48 & 8 & 32.015 & $\mathrm{p}=0.000$ \\
\hline Mother(alive) & 1048 & 98.5 & 16 & 1.5 & 589 & 98.2 & 11 & 1.8 & & n.s. \\
\hline Grandfather(alive) & 749 & 70.4 & 315 & 29.6 & 136 & 22.7 & 464 & 77.3 & 351.005 & $\mathrm{p}=0.000$ \\
\hline Grandmother(alive) & 989 & 93 & 75 & 7 & 323 & 53.8 & 277 & 46.2 & 351.98 & $\mathrm{p}=0.000$ \\
\hline Grandparents alive with them & 379 & 35.6 & 685 & 64.4 & 395 & 65.8 & 205 & 34.2 & 140.768 & $\mathrm{p}=0.000$ \\
\hline
\end{tabular}

Table 1 presents the composition of participants' families in Japan and Sri Lanka. Although there was little variation in living parents, there was a notable difference regarding living grandparents between the two countries. This is consistent with the World Health Organization (2012) report on life expectancy at birth, which placed Japan among the top 10 countries with an average life expectancy for females of 87 years and males of 80 years. Interestingly, $65.8 \%$ of students in Sri Lanka had lived with grandparents before they entered university compared with $35.6 \%$ in Japan, highlighting the existence of extended families in Sri Lanka. Chi-square tests showed living grandparents were significant in terms of the attitudes of male and female students in both countries $(\mathrm{p}=0.000)$. 
Table 2. Belief that Children Should Live with their Parents after Marriage

\begin{tabular}{|c|c|c|c|c|c|c|c|c|c|c|}
\hline \multirow{3}{*}{ Responses } & \multicolumn{4}{|c|}{ Japan(1) } & \multicolumn{4}{|c|}{ Sri Lanka(2) } & \multirow{2}{*}{$\chi^{2}$ test } & \multirow[b]{3}{*}{ Probability } \\
\hline & \multicolumn{2}{|c|}{ Yes } & \multicolumn{2}{|c|}{ No } & \multicolumn{2}{|c|}{ Yes } & \multicolumn{2}{|c|}{ No } & & \\
\hline & $\mathbf{N}$ & $\%$ & $\mathbf{N}$ & $\%$ & $\mathbf{N}$ & $\%$ & $\mathbf{N}$ & $\%$ & (1) vs. (2) & \\
\hline $\begin{array}{l}\text { 1.Better to live separately away from one's } \\
\text { parents as long as one can. }\end{array}$ & 154 & 14.5 & 910 & 85.5 & 11 & 1.8 & 577 & 96.2 & 66.98 & $P=0.000$ \\
\hline $\begin{array}{l}\text { 2. Better to live together with one's parents as } \\
\text { long as one can. }\end{array}$ & 113 & 10.6 & 951 & 89.4 & 374 & 62.3 & 214 & 35.7 & 511.425 & $P=0.000$ \\
\hline $\begin{array}{l}\text { 3.Better to live separately while one's parents } \\
\text { are doing well and live together once they are in } \\
\text { poor health. }\end{array}$ & 254 & 23.9 & 810 & 76.1 & 98 & 16.3 & 490 & 81.7 & 11.727 & $P=0.001$ \\
\hline $\begin{array}{l}\text { 4.Better to live together with one's parents once } \\
\text { they become a widow or widower. }\end{array}$ & 70 & 6.6 & 994 & 93.4 & 16 & 2.7 & 572 & 95.3 & 11.422 & $P=0.001$ \\
\hline $\begin{array}{l}\text { 5.Frequent mutual visit while living separately } \\
\text { would be best. }\end{array}$ & 379 & 35.6 & 685 & 64.4 & 86 & 14.3 & 502 & 83.7 & 82.534 & $P=0.000$ \\
\hline 6.No idea. & 94 & 8.8 & 970 & 91.2 & 15 & 2.5 & 573 & 95.5 & 24.263 & $P=0.000$ \\
\hline
\end{tabular}

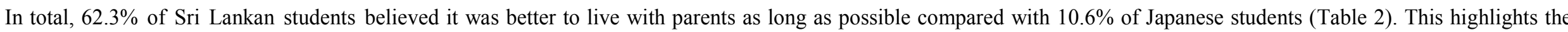

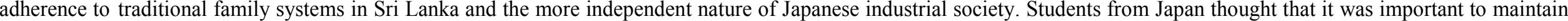

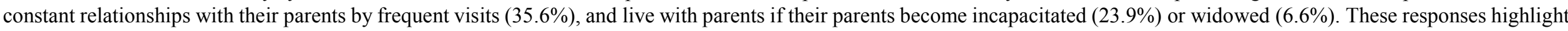
cultural and economic differences between Japan and Sri Lanka.

Table 3. Preferences about Residing with Parents

\begin{tabular}{|c|c|c|c|c|c|c|c|c|c|c|}
\hline \multirow{3}{*}{ Responses } & \multicolumn{4}{|c|}{$\operatorname{Japan}(1)$} & \multicolumn{4}{|c|}{ Sri Lanka(2) } & \multirow{3}{*}{$\frac{\chi^{2} \text { test }}{\text { (1) vs. (2) }}$} & \multirow[b]{3}{*}{ Probability } \\
\hline & \multicolumn{2}{|c|}{ Yes } & \multicolumn{2}{|c|}{ No } & \multicolumn{2}{|c|}{ Yes } & \multicolumn{2}{|c|}{ No } & & \\
\hline & $\mathbf{N}$ & $\%$ & $\mathbf{N}$ & $\%$ & $\mathbf{N}$ & $\%$ & $\mathbf{N}$ & $\%$ & & \\
\hline 1.Yes & 105 & 9.9 & 959 & 90.1 & 532 & 89.6 & 62 & 10.4 & 1023.29 & $P=0.000$ \\
\hline 2. Not yet decided. & 674 & 63.3 & 380 & 35.7 & 54 & 9.1 & 540 & 90.9 & 463.567 & $P=0.000$ \\
\hline 3.No & 285 & 26.8 & 779 & 73.2 & 8 & 1.3 & 586 & 98.6 & 169.555 & $P=0.000$ \\
\hline
\end{tabular}

As indicated in Table 3, a majority (89.6\%) of Sri Lankan students preferred to live with their parents, whereas only $9.9 \%$ of Japanese students reported such a preference. 
Table 4. Economic Support for Aging Parents

\begin{tabular}{|c|c|c|c|c|c|c|c|c|c|c|}
\hline \multirow{3}{*}{ Responses } & \multicolumn{4}{|c|}{ Japan(1) } & \multicolumn{4}{|c|}{ Sri Lanka(2) } & \multirow{2}{*}{$\chi^{2}$ test } & \multirow[b]{3}{*}{ Probability } \\
\hline & \multicolumn{2}{|c|}{ Yes } & \multicolumn{2}{|c|}{ No } & \multicolumn{2}{|c|}{ Yes } & \multicolumn{2}{|c|}{ No } & & \\
\hline & $\mathrm{N}$ & $\%$ & $\mathbf{N}$ & $\%$ & $\mathrm{~N}$ & $\%$ & $\mathrm{~N}$ & $\%$ & (1) vs. (2) & \\
\hline 1.Provide economic supports at all costs. & 271 & 25.5 & 793 & 74.5 & 423 & 70.9 & 174 & 29.1 & 323.826 & $P=0.000$ \\
\hline $\begin{array}{l}\text { 2.Depend on my economic condition,however I } \\
\text { would provide some support. }\end{array}$ & 656 & 61.7 & 408 & 38.3 & 173 & 28.9 & 424 & 71.1 & 163.329 & $P=0.000$ \\
\hline $\begin{array}{l}\text { 3. Could not provide economic supports under } \\
\text { severe economic conditions. }\end{array}$ & 110 & 10.3 & 954 & 89.7 & 5 & 0.8 & 592 & 99.2 & 53.567 & $P=0.000$ \\
\hline $\begin{array}{l}\text { 4.Social supports such as pensions, should be } \\
\text { provided. }\end{array}$ & 27 & 2.5 & 1037 & 97.5 & 4 & 0.7 & 593 & 99.3 & 7.283 & $P=007$ \\
\hline
\end{tabular}

In Japan, $25.5 \%$ of students believed in providing economic support to parents at all costs compared to $70.9 \%$ of students in Sri Lanka (Table 4). This shows that the traditional social value of providing economic support for aging parents continues in the modern social context. In addition, $61.7 \%$ of students in Japan and $28.9 \%$ in Sri Lanka were concerned about their financial capability to help their parents, but believed in providing some support for parents. Overall, most students (about $87 \%$ in Japan and $99 \%$ in Sri Lanka) had positive attitudes toward providing economic support for aging parents.

Table 5 presents students' views about taking care of their aging parents' daily life needs. More students in Sri Lanka (41.7\%) than Japan (11.3\%) believed that children should take care of parents' daily life needs. In both countries, about $40 \%$ of students thought that children should take care of parents for the most part, with social support provided when children were unable to take care of parents.

Table 5. Taking Care of Aging Parents' Daily Life Needs

\begin{tabular}{|c|c|c|c|c|c|c|c|c|c|c|}
\hline \multirow{3}{*}{ Responses } & \multicolumn{4}{|c|}{ Japan(1) } & \multicolumn{4}{|c|}{ Sri Lanka(2) } & \multirow{2}{*}{$\chi^{2}$ test } & \multirow{3}{*}{ Probability } \\
\hline & \multicolumn{2}{|c|}{ Yes } & \multicolumn{2}{|c|}{ No } & \multicolumn{2}{|c|}{ Yes } & \multicolumn{2}{|c|}{ No } & & \\
\hline & $\mathbf{N}$ & $\%$ & $\mathbf{N}$ & $\%$ & $\mathbf{N}$ & $\%$ & $\mathbf{N}$ & $\%$ & (1) vs. (2) & \\
\hline 1.Their children should take care of them & 120 & 11.3 & 944 & 88.7 & 250 & 41.7 & 350 & 58.3 & $204.893, \mathrm{df}=1$ & $p=0.000$ \\
\hline $\begin{array}{l}\text { 2.Both their children and society should take } \\
\text { care of them }\end{array}$ & 443 & 41.6 & 621 & 58.4 & 106 & 17.7 & 494 & 82.3 & $99.698, \mathrm{df}=1$ & $p=0.000$ \\
\hline $\begin{array}{l}\text { 3.Children should take care of them for the most } \\
\text { part,and social support should be provided when } \\
\text { children aren't able to take care of them. }\end{array}$ & 423 & 39.8 & 641 & 60.2 & 240 & 40 & 360 & 60 & & n.s. \\
\hline $\begin{array}{l}\text { 4.Society should provide support and children } \\
\text { should supplement what society cannot provide. }\end{array}$ & 76 & 7.1 & 988 & 92.9 & 0 & 0 & 600 & 100 & & n.s. \\
\hline $\begin{array}{l}\text { 5.All of the supports should be provided by } \\
\text { society. }\end{array}$ & 2 & 0.2 & 1,062 & 99.8 & 5 & 0.8 & 595 & 99.2 & & n.s. \\
\hline
\end{tabular}

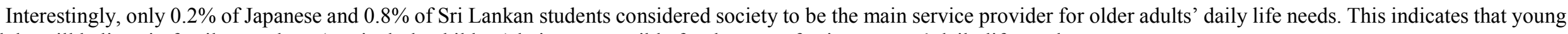
adults still believe in family members (particularly children) being responsible for the care of aging parents' daily life needs. 
Table 6. Taking Care of Aging Parents in Poor Health or Bedridden as the Sole Caregiver

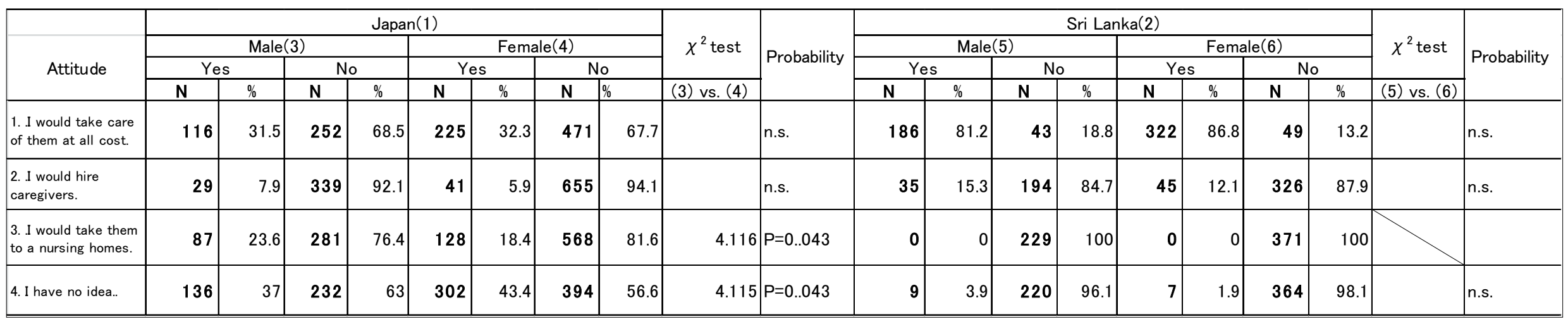

Table 6 shows that in Japan, $7.9 \%$ of male and $5.9 \%$ of female students believed in employing caregivers to support their parents, with this belief held by $15.3 \%$ of male and $12.1 \%$ of female students in Sri Lanka. In both countries, more females than males believed in taking sole caregiving responsibility at any cost (31.5\% of males vs. $32.3 \%$ of females in Japan; $81.2 \%$ of males vs. $86.8 \%$ of females in Sri Lanka). Overall, Sri Lankan students had higher rates of positive responses in terms of providing care at all costs than Japanese students.

Table 7. Seeking Institutional Care for Aging Parents

\begin{tabular}{|c|c|c|c|c|c|c|c|c|c|c|}
\hline \multirow{4}{*}{ Attitude } & \multicolumn{8}{|c|}{ Total } & \multirow{4}{*}{$\begin{array}{l}\chi^{2} \text { test } \\
\text { (1) vs. (2) }\end{array}$} & \multirow[b]{4}{*}{ Probability } \\
\hline & \multicolumn{4}{|c|}{ Japan(1) } & \multicolumn{4}{|c|}{ Sri Lanka(2) } & & \\
\hline & \multicolumn{2}{|c|}{ Yes } & \multicolumn{2}{|c|}{ No } & \multicolumn{2}{|c|}{ Yes } & \multicolumn{2}{|c|}{ No } & & \\
\hline & $\mathbf{N}$ & $\%$ & $\mathbf{N}$ & $\%$ & \begin{tabular}{l|l}
$\mathbf{N}$ \\
\end{tabular} & $\%$ & $\mathbf{N}$ & $\%$ & & \\
\hline $\begin{array}{l}\text { 1.It is impossible for family } \\
\text { members to maintain care } \\
\text { giving responsibilities. }\end{array}$ & 424 & 39.8 & 640 & 60.2 & 13 & 2.2 & 587 & 97.8 & 281.326 & $p=0.000$ \\
\hline $\begin{array}{l}\text { 2.Any efforts should be } \\
\text { done in order to avoid it. }\end{array}$ & 495 & 46.5 & 569 & 53.5 & 377 & 62.8 & 223 & 37.2 & 40.922 & $p=0.000$ \\
\hline $\begin{array}{l}\text { 3.The sons or daughters } \\
\text { adopting these ideas are } \\
\text { undutiful to their parents. }\end{array}$ & 26 & 2.4 & 1,038 & 97.6 & 162 & 27.1 & 438 & 72.9 & 230.851 & $p=0.000$ \\
\hline 4.I have no idea.. & 119 & 11.2 & 945 & 88.8 & 58 & 9.7 & 542 & 90.3 & & n.s. \\
\hline
\end{tabular}


Table 7 indicates that the majority of participants did not consider institutional care (e.g., nursing homes) appropriate for aging parents (Japan, 46.5\%; Sri Lanka, 62.8\%). In addition, $2.4 \%$ of Japanese and $27.1 \%$ Sri Lankan students thought that sons and daughters who have such thoughts are not dutiful to their parents. However, $39.8 \%$ of Japanese and $2.2 \%$ of Sri Lankan students believed in seeking institutional care if family members were unable to maintain caregiving responsibilities. The strong attitude toward avoiding institutional care in both countries suggests that the impact of traditions that uphold the honor of the family is being challenged.

Table 8. Sustainability of Traditional Norms

\begin{tabular}{|c|c|c|c|c|c|c|c|c|c|c|}
\hline \multirow{4}{*}{ Responses } & \multicolumn{8}{|c|}{ Total } & \multirow{4}{*}{$\chi^{2}$ test } & \multirow{4}{*}{ Probability } \\
\hline & \multicolumn{4}{|c|}{ Japan(1) } & \multicolumn{4}{|c|}{ Sri Lanka(2) } & & \\
\hline & \multicolumn{2}{|c|}{ Yes } & \multicolumn{2}{|c|}{ No } & \multicolumn{2}{|c|}{ Yes } & \multicolumn{2}{|c|}{ No } & & \\
\hline & $\mathbf{N}$ & $\%$ & $\mathbf{N}$ & $\%$ & $\mathbf{N}$ & $\%$ & $\mathbf{N}$ & $\%$ & & \\
\hline $\begin{array}{l}\text { 1.Yes,it should be } \\
\text { sustained ,because it is } \\
\text { a very good social } \\
\text { custom. }\end{array}$ & 231 & 21.7 & 833 & 78.3 & 442 & 73.7 & 158 & 26.3 & 429.963 & $P=0.000$ \\
\hline 2.It is not a good thing. & 87 & 8.2 & 977 & 91.8 & 9 & 1.5 & 591 & 98.5 & 31.59 & $P=0.000$ \\
\hline $\begin{array}{l}\text { 3.It does not fit modern } \\
\text { society. }\end{array}$ & 424 & 39.8 & 640 & 60.2 & 50 & 8.3 & 550 & 91.7 & 187.064 & $P=0.000$ \\
\hline 4.II have no idea.. & 322 & 30.3 & 742 & 69.7 & 99 & 16.5 & 501 & 83.5 & 38.453 & $P=0.000$ \\
\hline
\end{tabular}

A majority (73.7\%) of Sri Lankan students believed in sustaining traditional social values and norms by taking care of aging parents while living with them (Table 8). In contrast, only $21.7 \%$ of Japanese students shared this belief. 
Table 9. Meaning of "Being Good to One's Parents"

\begin{tabular}{|c|c|c|c|c|c|c|c|c|c|c|}
\hline \multirow{4}{*}{ Responses } & \multicolumn{8}{|c|}{ Total } & \multirow{3}{*}{$\chi^{2}$ test } & \multirow{4}{*}{ Probability } \\
\hline & \multicolumn{4}{|c|}{ Japan(1) } & \multicolumn{4}{|c|}{ Sri Lanka(2) } & & \\
\hline & \multicolumn{2}{|c|}{ Yes } & \multicolumn{2}{|c|}{ No } & \multicolumn{2}{|c|}{ Yes } & \multicolumn{2}{|c|}{ No } & & \\
\hline & $\mathbf{N}$ & $\%$ & $\mathbf{N}$ & $\%$ & $\mathbf{N}$ & $\%$ & $\mathbf{N}$ & $\%$ & (1) vs. (2) & \\
\hline $\begin{array}{l}\text { 1.Companionship or } \\
\text { frequent visiting. }\end{array}$ & 689 & 64.8 & 375 & 35.2 & 286 & 47.7 & 314 & 52.3 & 46.18 & $P=0.000$ \\
\hline 2.caregiving. & 199 & 18.7 & 865 & 81.3 & 271 & 45.2 & 329 & 54.8 & 132.57 & $P=0.000$ \\
\hline $\begin{array}{l}\text { 3..Supporting them } \\
\text { economically. }\end{array}$ & 170 & 15.9 & 894 & 84.1 & 23 & 3.8 & 577 & 96.2 & 55.183 & $P=0.000$ \\
\hline $\begin{array}{l}\text { 4...Living independently } \\
\text { without any supports } \\
\text { from one's parents.. }\end{array}$ & 630 & 59.2 & 434 & 40.8 & 78 & 13.1 & 522 & 86.9 & 335.148 & $P=0.000$ \\
\hline
\end{tabular}

As indicated in Table 9, the meaning of "being good to one's parents" differed by country; $64.8 \%$ of Japanese and $47.7 \%$ of Sri Lankan students felt that this meant companionship or frequent visits, whereas $18.7 \%$ of Japanese and $45.2 \%$ of Sri Lankan students understood it to mean caregiving. Over half (59.2\%) of the Japanese students agreed that being good to one's parents meant "living independently without any support from one's parents," whereas only $13.1 \%$ of students in Sri Lanka agreed with this item.

Table 10. Seriousness of the Problem of Population Aging in Japan and Sri Lanka

\begin{tabular}{|c|c|c|c|c|c|c|c|c|c|c|c|c|}
\hline \multirow{4}{*}{ Issues } & \multicolumn{4}{|c|}{ Japan (1) } & \multicolumn{4}{|c|}{ Sri Lanka (2) } & \multicolumn{4}{|c|}{ Total (3) } \\
\hline & \multirow{2}{*}{\multicolumn{2}{|c|}{$\begin{array}{l}\text { Male } \\
\text { Yes }\end{array}$}} & \multirow{2}{*}{\multicolumn{2}{|c|}{$\begin{array}{c}\text { Female } \\
\text { Yes }\end{array}$}} & \multirow{2}{*}{\multicolumn{2}{|c|}{$\begin{array}{l}\text { Male } \\
\text { Yes }\end{array}$}} & \multirow{2}{*}{\multicolumn{2}{|c|}{$\frac{\text { Female }}{\text { Yes }}$}} & \multirow{2}{*}{\multicolumn{2}{|c|}{$\begin{array}{c}\text { Japan } \\
\text { Yes }\end{array}$}} & \multicolumn{2}{|c|}{ Sri Lanka } \\
\hline & & & & & & & & & & & $\mathrm{Y}$ & \\
\hline & $\mathrm{N}$ & $\%$ & $\mathrm{~N}$ & $\%$ & $\mathrm{~N}$ & $\%$ & $\mathrm{~N}$ & $\%$ & $\mathrm{~N}$ & $\%$ & $\mathrm{~N}$ & $\%$ \\
\hline 1. Very serious issues. & 283 & 76.8 & 560 & 80.5 & 91 & 39.7 & 219 & 59.1 & 843 & 79.2 & 309 & 51.5 \\
\hline 2. No idea. & 81 & 22.1 & 133 & 19.1 & 130 & 56.8 & 134 & 36.1 & 214 & 20.1 & 264 & 44.1 \\
\hline 3. No problem. & 4 & 1.1 & 3 & 0.4 & 8 & 3.5 & 18 & 4.8 & 7 & 0.7 & 26 & 4.4 \\
\hline Total & 368 & & 696 & & 229 & & 371 & & 1064 & & 600 & \\
\hline Probability & $\chi^{2}$ test: n.s & & & & $\chi^{2}$ test: 2 & $25, d f=2, r$ & .000 & & $\chi^{2}$ test: 1 & $018, \mathrm{df}=$ & .000 & \\
\hline
\end{tabular}


In total, $79.2 \%$ of Japanese students and $51.5 \%$ of Sri Lankan students thought that population aging was a very serious issue. However, $20.1 \%$ of Japanese and $44.1 \%$ of Sri Lankan students were unaware of the magnitude of the problem. In Sri Lanka, more female students agreed the aging population was a serious issue than male students ( $\mathrm{p}=0.000$ ).

Table 11. Perceptions/Images of Older People in Japan and Sri Lanka (Multiple Responses)

\begin{tabular}{|c|c|c|c|c|c|c|c|c|c|c|}
\hline \multirow{3}{*}{ Image of older people } & \multicolumn{4}{|c|}{ Japan(1) } & \multicolumn{4}{|c|}{ Sri Lanka(2) } & \multirow{3}{*}{$\frac{\chi^{2} \text { test }}{\text { (1) vs. (2) }}$} & \multirow[b]{3}{*}{ Probability } \\
\hline & \multicolumn{2}{|c|}{ Yes } & \multicolumn{2}{|c|}{ No } & \multicolumn{2}{|c|}{ Yes } & \multicolumn{2}{|c|}{ No } & & \\
\hline & $\mathbf{N}$ & $\%$ & $\mathbf{N}$ & $\%$ & $\mathbf{N}$ & $\%$ & $\mathrm{~N}$ & $\%$ & & \\
\hline $\begin{array}{l}\text { 1.People who are in poor health both physically and mentally } \\
\text { and have anxiety about it. }\end{array}$ & 774 & 72.7 & 290 & 27.3 & 478 & 79.7 & 122 & 20.3 & 9.868 & $p=0.002$ \\
\hline $\begin{array}{l}\text { 2.People who have a good amount of experience and } \\
\text { knowledge. }\end{array}$ & 730 & 68.6 & 334 & 31.4 & 229 & 38.2 & 371 & 61.8 & 145.61 & $p=0.000$ \\
\hline $\begin{array}{l}3 \text { People who are addicted to something of interest that uses } \\
\text { plenty of time. }\end{array}$ & 444 & 41.7 & 620 & 58.3 & 44 & 7.3 & 556 & 92.7 & 218.995 & $p=0.000$ \\
\hline 4. People who are not free from traditions. & 315 & 29.6 & 749 & 70.4 & 82 & 13.7 & 518 & 86.3 & 53.651 & $p=0.000$ \\
\hline 5.People who are isolated and have very few relationships. & 272 & 25.6 & 792 & 74.4 & 87 & 14.5 & 513 & 85.5 & 27.756 & $p=0.000$ \\
\hline 6.People who have less income and have anxiety about it. & 260 & 24.4 & 804 & 75.6 & 34 & 5.7 & 566 & 94.3 & 92.914 & $p=0.000$ \\
\hline $\begin{array}{l}\text { 7.People who contribute to society,volunteering and } \\
\text { performing community services. }\end{array}$ & 184 & 17.3 & 880 & 82.7 & 62 & 10.3 & 538 & 89.7 & 14.752 & $p=0.000$ \\
\hline 8.People who have healyhy daily lives. & 179 & 16.8 & 885 & 83.2 & 23 & 3.8 & 577 & 96.2 & 60.697 & $p=0.000$ \\
\hline $\begin{array}{l}\text { 9.People who are satisfied with their lives } \\
\text { economically, having savings and their own houses. }\end{array}$ & 176 & 16.5 & 888 & 83.5 & 22 & 3.7 & 578 & 96.3 & 60.663 & $p=0.000$ \\
\hline 10.Useless people who do not work anymore. & 35 & 3.3 & 1029 & 96.7 & 23 & 3.8 & 577 & 96.2 & & n.s. \\
\hline
\end{tabular}

Note)Image of older people consists of FAQ-positive(No.of items:2,3,7,8,9) and FAQ-negative(No. of items:1,4,5,6,10)

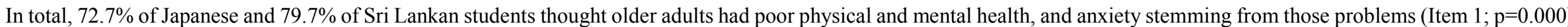

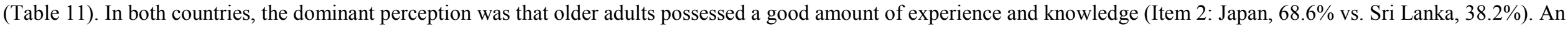

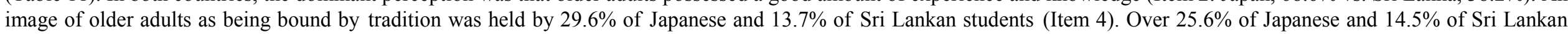

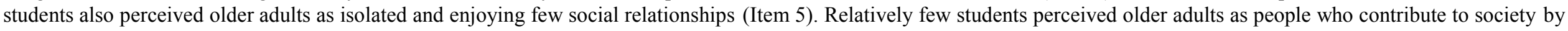


volunteering and performing community services (Item 7; 17.3\% of Japanese and 10.3\% of Sri Lankan students). Overall, many students held a negative image of older adults, with the ratios of participants who responded "yes" to these items were higher in Japan than in Sri Lanka. Japanese students may be particularly concerned with the problem of population aging because they carry heavier economic, mental, and physical burdens as caregivers based on Japan's super-aged society.

Table 12. Treating Older Adults Well in Japan and Sri Lanka

\begin{tabular}{|c|c|c|c|c|c|c|c|c|c|c|c|c|}
\hline \multirow{4}{*}{ Attitude } & \multicolumn{4}{|c|}{ Japan } & \multicolumn{4}{|c|}{ Sri Lanka } & \multicolumn{4}{|c|}{ Total } \\
\hline & \multirow{2}{*}{\multicolumn{2}{|c|}{$\frac{\text { Male }}{\text { Yes }}$}} & \multicolumn{2}{|c|}{ Female } & \multicolumn{2}{|c|}{ Male } & \multicolumn{2}{|c|}{ Female } & \multicolumn{2}{|c|}{ Japan } & \multicolumn{2}{|c|}{ Sri Lanka } \\
\hline & & & \multicolumn{2}{|c|}{ Yes } & \multicolumn{2}{|c|}{ Yes } & \multicolumn{2}{|c|}{ Yes } & \multicolumn{2}{|c|}{ Yes } & \multicolumn{2}{|c|}{ Yes } \\
\hline & $\mathrm{N}$ & $\%$ & $\mathbf{N}$ & $\%$ & $\mathrm{~N}$ & $\%$ & $\mathrm{~N}$ & $\%$ & $\mathrm{~N}$ & $\%$ & $\mathbf{N}$ & $\%$ \\
\hline 1. Agree. & 50 & 13.6 & 56 & 8 & 37 & 16.2 & 49 & 13.2 & 106 & 10 & 86 & 14.3 \\
\hline 2.Partially agree. & 176 & 47.8 & 336 & 48.3 & 129 & 56.3 & 192 & 51.8 & 512 & 48.1 & 321 & 53.5 \\
\hline 3.Agree a little. & 136 & 37 & 276 & 39.7 & 55 & 24 & 123 & 33.2 & 412 & 38.7 & 178 & 29.7 \\
\hline 4. Disagree completely. & 6 & 1.6 & 28 & 4 & 8 & 3.5 & 7 & 1.9 & 34 & 3.2 & 15 & 2.5 \\
\hline Total & 36 & & 69 & & 2 & & 37 & & 1064 & & 600 & \\
\hline Probability & $x^{2}$ test & 2.194 & $-2-0$ & & $x^{2} t$ & 00 & $f-2 n-1$ & 076 & $\chi^{2}$ tes & 8.0 & $\mathrm{df}=3$, & .000 \\
\hline
\end{tabular}

Table 12 shows students' attitudes toward appropriate treatment of older adults in Japan and Sri Lanka. Overall, students' attitudes were similar in both countries, with a tendency to treat older people well in their communities shown by $58.1 \%$ of Japanese and $67.8 \%$ of Sri Lankan students.

Table 13. Opinions on the Existence of Discrimination and Prejudice in Japan and Sri Lanka, with Reference to Age

\begin{tabular}{|c|c|c|c|c|c|c|c|c|c|c|c|c|}
\hline \multirow{4}{*}{ Responses } & \multicolumn{4}{|c|}{ Japan(1) } & \multicolumn{4}{|c|}{ Sri Lanka(2) } & \multicolumn{4}{|c|}{ Total(3) } \\
\hline & \multirow{2}{*}{\multicolumn{2}{|c|}{$\begin{array}{l}\text { Male } \\
\text { Yes }\end{array}$}} & \multicolumn{2}{|c|}{ Female } & \multicolumn{2}{|c|}{$\begin{array}{l}\text { Male } \\
\text { Yec }\end{array}$} & \multirow{2}{*}{\multicolumn{2}{|c|}{$\begin{array}{c}\text { Female } \\
\text { Yes }\end{array}$}} & \multirow{2}{*}{\multicolumn{2}{|c|}{$\frac{\text { Japan }}{\text { Yes }}$}} & \multicolumn{2}{|c|}{ Sri Lanka } \\
\hline & & & \multicolumn{2}{|c|}{ Yes } & \multicolumn{2}{|c|}{ Yes } & & & & & \multicolumn{2}{|c|}{ Yes } \\
\hline & & $\%$ & $\mathbf{N}$ & $\%$ & $\mathbf{N}$ & $\%$ & $\mathrm{~N}$ & $\%$ & $\mathrm{~N}$ & $\%$ & $\mathrm{~N}$ & $\%$ \\
\hline 1. Yes,very many & 42 & 11.4 & 50 & 7.2 & 104 & 45.4 & 174 & 46.9 & 92 & 8.6 & 278 & 46.3 \\
\hline 2. Yes,they do. & 133 & 36.1 & 229 & 32.9 & 105 & 45.9 & 181 & 48.8 & 362 & 34 & 286 & 47.7 \\
\hline 3. Sometimes. & 142 & 38.6 & 326 & 46.8 & 20 & 8.7 & 16 & 4.3 & 468 & 44 & 36 & 6 \\
\hline 4. Very few. & 44 & 12 & 86 & 12.4 & 0 & 0 & 0 & 0 & 130 & 12.2 & 0 & 0 \\
\hline 5. Not at all. & 7 & 1.9 & 5 & 0.7 & 0 & 0 & 0 & 0 & 12 & 1.2 & 0 & 0 \\
\hline Total & \multicolumn{2}{|c|}{368} & \multicolumn{2}{|c|}{696} & \multicolumn{2}{|c|}{229} & \multicolumn{2}{|c|}{371} & \multicolumn{2}{|c|}{1064} & \multicolumn{2}{|c|}{600} \\
\hline Probability & \multicolumn{4}{|c|}{$\chi^{2}$ test: $12.471, \mathrm{df}=4, \mathrm{p}=0.014$} & \multicolumn{4}{|c|}{$\chi^{2}$ test: n.s. } & \multicolumn{4}{|c|}{$\chi^{2}$ test: $526.235, \mathrm{df}=4, P=0.000$} \\
\hline
\end{tabular}

We examined students' attitudes toward discrimination against and prejudices about older adults. There were high levels of discrimination and prejudice in Japanese and Sri Lankan 
social contexts (Table 13). There was a significant correlation $(\mathrm{p}=0.000)$ between the understanding of discrimination/prejudice against older adults and the perceptions of aging in both countries.

Table 14. Interest in Intergenerational Exchanges

\begin{tabular}{|c|c|c|c|c|c|c|c|c|c|c|c|c|}
\hline \multirow{4}{*}{ Responses } & \multicolumn{4}{|c|}{ Japan(1) } & \multicolumn{4}{|c|}{ Sri Lanka(2) } & \multicolumn{4}{|c|}{ Total(3) } \\
\hline & \multirow{2}{*}{\multicolumn{2}{|c|}{$\begin{array}{l}\text { Male } \\
\text { Yes }\end{array}$}} & \multirow{2}{*}{\multicolumn{2}{|c|}{$\begin{array}{c}\text { Female } \\
\text { Yes }\end{array}$}} & \multirow{2}{*}{\multicolumn{2}{|c|}{$\begin{array}{l}\text { Male } \\
\text { Yes }\end{array}$}} & \multirow{2}{*}{\multicolumn{2}{|c|}{$\begin{array}{c}\text { Female } \\
\text { Yes }\end{array}$}} & \multirow{2}{*}{\multicolumn{2}{|c|}{$\begin{array}{l}\text { Japan } \\
\text { Yes }\end{array}$}} & \multirow{2}{*}{\multicolumn{2}{|c|}{$\frac{\text { Sri Lanka }}{\text { Yes }}$}} \\
\hline & & & & & & & & & & & & \\
\hline & $\mathbf{N}$ & $\%$ & $\mathbf{N}$ & $\%$ & $\mathbf{N}$ & $\%$ & $\mathbf{N}$ & $\%$ & $\mathrm{~N}$ & $\%$ & $\mathbf{N}$ & $\%$ \\
\hline 1. Yes. & 182 & 49.5 & 390 & 56 & 133 & 58.1 & 280 & 75.5 & 572 & 53.8 & 413 & 68.8 \\
\hline 2. No,specific interest. & 170 & 46.2 & 283 & 40.7 & 94 & 41 & 90 & 24.3 & 454 & 42.6 & 184 & 30.7 \\
\hline 3. No. & 16 & 4.3 & 23 & 3.3 & 2 & 0.9 & 1 & 0.3 & 38 & 3.6 & 3 & 5 \\
\hline Total & \multicolumn{2}{|c|}{368} & \multicolumn{2}{|c|}{696} & \multicolumn{2}{|c|}{229} & \multicolumn{2}{|c|}{371} & \multicolumn{2}{|c|}{1064} & \multicolumn{2}{|c|}{600} \\
\hline Probability & \multicolumn{4}{|c|}{$\chi^{2}$ test: n.s. } & \multicolumn{4}{|c|}{$\chi^{2}$ test: $20.271, \mathrm{df}=2, \mathrm{p}=0.000$} & \multicolumn{4}{|c|}{$\chi^{2}$ test: $43.831, \mathrm{df}=1, \mathrm{p}=0.000$} \\
\hline
\end{tabular}

We investigated students' interest in intergenerational exchanges (Table 14). A significant percentage of students (Japan, 53.8\%; Sri Lanka, 68.8\%; $\mathrm{p}=0.000)$ had an interest in intergenerational exchanges. In Sri Lanka, $75.5 \%$ of female students had positive attitudes toward intergenerational exchanges compared with $58.1 \%$ of male students ( $\mathrm{p}=0.000$ ). In the Japanese sample, positive attitudes toward intergenerational exchanges were similar in females and males (56.0\% vs. $49.5 \%)$.

Table 15. Partial Correlation Coefficients Matrix among 5 items: Interest, Attitude, Discrimination, Intergenerational Exchange, and Knowledge about the Aged and Aging (statistically controlled for age and sex).

\begin{tabular}{|c|c|c|c|c|c|c|c|c|c|c|}
\hline \multirow{2}{*}{ Questions } & \multicolumn{5}{|c|}{ Japan $(\mathrm{N}=1060)$} & & \multicolumn{4}{|c|}{ Sri Lanka $(\mathrm{N}=591)$} \\
\hline & 1 & 2 & 3 & 4 & 5 & 1 & 2 & 3 & 4 & 5 \\
\hline \multicolumn{11}{|l|}{ 1.Interest in the issues of aging } \\
\hline $\begin{array}{l}\text { 2.Discriminations or prejudices toward } \\
\text { the aged }\end{array}$ & $\begin{array}{l}-0.09 \\
p<.01\end{array}$ & & & & & & & & & \\
\hline $\begin{array}{l}\text { 3.Interests to intergenerational exchange } \\
\text { activities }\end{array}$ & $\begin{array}{c}.32 \\
p<.01 \\
\end{array}$ & & & & & $\begin{array}{c}.24 \\
p<.01 \\
\end{array}$ & $\begin{aligned} .10 \\
p<.01 \\
\end{aligned}$ & & & \\
\hline $\begin{array}{l}\text { 4.Facts on Aging Quiz(FAQ) including } \\
\text { positive knowledges about the aged }\end{array}$ & $\begin{array}{l}-0.07 \\
p<.05\end{array}$ & $\begin{array}{l}.10 \\
p<.01\end{array}$ & $\begin{array}{l}-0.14 \\
p<.01\end{array}$ & & & $\begin{array}{l}-0.10 \\
p<.05\end{array}$ & & $\begin{array}{l}-0.18 \\
p<.01\end{array}$ & & \\
\hline $\begin{array}{l}\text { 5.Facts on Aging Quiz(FAQ) including } \\
\text { negative knowledges about the aged }\end{array}$ & & $\begin{array}{l}-0.17 \\
p<.01\end{array}$ & $\begin{array}{l}.10 \\
p<.01\end{array}$ & $\begin{array}{l}-0.08 \\
p<.01\end{array}$ & & & & & $\begin{array}{l}-0.07 \\
p<.10\end{array}$ & \\
\hline Significance level: $: p<.10, p<.05, p<.01$ & \multicolumn{3}{|c|}{;age and sex were controlled } & & & & & & & \\
\hline
\end{tabular}


Inter-correlations among items covering "interest in the issue of aging societies," "discrimination or prejudice toward the aged," "interest in intergenerational exchange activities," and "FAQ (positive and negative) knowledge about the aged" were analyzed using partial correlation coefficients (controlled for age and sex). In the Japanese sample, "interest in the issue of aging" showed statistically significant correlations with "discrimination or prejudices toward the aged," "interest in intergenerational exchange activities," and "FAQ-positive." The Sri Lankan sample showed similar results.

\section{Perceptions of the Terms "Elderly Person" or "Senior Citizen"}

When the scores for discrimination/prejudice toward older adults were higher, the scores for each factor were statisticswise significantly lower. We also found that when scores for interest in intergenerational exchange items were higher, scores for each factor were statisticswise significantly higher. Furthermore, when FAQ-positive scores for the five items shown in Table 11 were higher, scores for each factor were statistiswise significantly higher; however, FAQ-negative scores for the items in Table 11 were significantly lower. These results indicate that young adults' positive attitudes and affirmative behaviors regarding older adults tended to create more comfortable and better conditions for aged people in their daily lives, perhaps through intergenerational activities between young and older adults and through aging education in schools (Kaplan, Kusano, Tsuji, \& Hisamichi, 1998).

\section{Discussion}

\section{Students' Opinions and Images about Aged Parents}

In Japan, students commonly reported that "frequent mutual visits while living separately would be best" $(35 \%)$, whereas the majority $(62 \%)$ of Sri Lankan students reported it was "better to live together with one's parents as long as one can." Students' preferences about residing with their parents varied between the two countries, with a majority of Sri Lankan students (about 90\%) indicating they would prefer to live with their parents compared with about $10 \%$ of Japanese students.

Interestingly, views on taking care of aging parents' daily life needs differed between the two countries. More Sri Lankan students believed that family members (particularly children) should be responsible for the care of aging parents' daily life needs at all costs (about $42 \%$ in Sri Lanka vs. about $11 \%$ in Japan). In addition, Sri Lankan students tended to have a higher ratio of positive responses to items concerning taking care of aging parents in poor health/bedridden as the sole caregiver than
Japanese students (about 84\% in Sri Lanka vs. about 32\% in Japan).

Students in both countries held strong attitudes towards avoiding seeking institutional care, which suggests the impact of traditional beliefs that uphold the honor of the family which is being challenged. Positive responses for the item "any efforts should be made to avoid it [institutional care]" were most common in both countries (about $47 \%$ in Japan; about $63 \%$ in Sri Lanka). In terms of "children should support their parents while living with their parents," more students in Sri Lanka (about 74\%) agreed that this "should be sustained because it is a good social custom and a traditional norm" than in Japan (about $22 \%$ ). This suggests that many Sri Lankan students continue to believe it is the responsibility of families to perform traditional functions of care for aging parents.

The cultural and economic differences between the two countries were evident in students' responses, which highlighted the industrial and independent nature of the population in Japan compared with the traditional dependent culture in Sri Lankan families. Overall, young adults' opinions and perceptions toward their parents in Sri Lanka differed from those in Japan. In the Japanese context, this may be explained by changes in the civil code after World War II; children's responsibility for supporting and caring for aging parents was strictly determined from the beginning of the Meiji Restoration in 1868 to 1945 (the end of World War II), but this responsibility eased during the period after the war (Yokoyama, 2000). In contrast, children's responsibility for supporting and caring for their aging parents at any cost remains strictly delineated in the Sri Lankan cultural and religious context. However, changing family structures in Sri Lanka are likely to have a social impact for aging parents. The traditional extended family has undergone dramatic change, and Sri Lanka has an increasing number of nuclear families. In addition, the trend of migration to urban areas and other countries for work and education is likely to become widespread and be accompanied by a change in the traditional function of the family as a social institution. In particular, the function of providing care for aging parents in the family environment has been challenged by this structural change in traditional extended families. If older adults are helpless in their own family and home environments, they will be compelled to leave their hometowns and migrate to urban areas to receive care and support from their children (Dhanapala \& Yaguchi, 2015). This means that Sri Lankan families may experience drastic changes in consciousness and behaviors in supporting and caring for aging parents, despite the traditional function of the family as a social system.

\section{Interest in the Problem of Population Aging}

We found that overall, students' consciousness of the issue of population aging were similar in Japan and Sri 
Lanka, with interest in this issue almost the same in both samples (81.4\% in Japan; $80.7 \%$ in Sri Lanka). This suggests that university students in both countries had similar levels of knowledge and concern about the problem of population aging despite different views about the seriousness of Sri Lanka's aging society and Japan's super-aged society.

Participating students in Japan and Sri Lanka indicated they understood the magnitude of the problem of population aging. Aging was regarded as a serious problem; however, significantly more female students in Sri Lanka felt that it was a serious issue than male students (males about $40 \%$ vs. females about $60 \%$ ). This might be because daughters have a greater burden of support and care for aging parents than sons. In contrast, male and female students in Japan showed similar attitudes towards the magnitude of the problem of population aging (males about $77 \%$; females about $80 \%$ ). This might reflect a belief that males and females in Japan are responsible for an equal care burden for aging parents.

\section{Intergenerational Activities}

We investigated students' interest in intergenerational exchanges. In both countries, a majority of students indicated an interest in such exchanges (about 54\% in Japan and about $69 \%$ in Sri Lanka). However, both sexes in the Sri Lankan group had more positive responses toward intergenerational exchanges than the Japanese group (males: about 58\% in Sri Lanka vs. about 50\% in Japan; females: about $76 \%$ in Sri Lanka vs. $56 \%$ in Japan). These results indicated that in both countries, females had a more positive attitude to intergenerational exchanges than males. Over $70 \%$ of students agreed that older adults are in poor physical and mental health and have anxiety about their health. Over $60 \%$ of students who were affirmative (approving) of the attitude of discrimination also agreed with the idea of older adults as people with a good amount of experience and knowledge.

In summary, many young adults believed in traditional forms of caregiving with social support, and they appeared to have developed perceptions and opinions to help prepare them to face the challenges of population aging. In both Japan and Sri Lanka, female students were more concerned about population aging. However, most students indicated they were prepared to take up a caring role for their aging parents rather than place them in an institution that provided formal care. In terms of ageism, young adults' reported perceptions that affirmed the prevalence of prejudice. In Sri Lanka, they were not aware of the concept of "active aging," which refers to continuing to work and participating in events in their regional communities during old age.

Awareness/consciousness about population aging among young adults differs according to the social perceptions they develop about aging, and is significant in building intergenerational relationships. Although older adults are considered to be resources and repositories of life experience, some negative perceptions and attitudes still prevail. However, the literature suggests that positive exposure to older people can challenge ageist views (Kusano, Watanabe, Uchida, Yasunaga, \& Yamanouchi, 2015).

\section{Conclusions}

This study focused on university students' consciousness about supporting their aging parents, and their concern about the problem of population aging. The present study provides a foundation for further in-depth studies on these issues. Our study only touched the "tip of the iceberg" in terms of perceptions and opinions university students hold about supporting aging parents. We found that students are strongly influenced by the traditions and customs of their country. Our findings also raised a number of issues for formulating and amending appropriate social policy for the welfare of older adults in Japan and Sri Lanka. Some important implications of this study are:

1. There is a need to conduct more quantitative and qualitative studies among young adults across both countries, as the present samples drawn from cities had limitations. The opinions of rural young adults may differ markedly from those of urban young adults. Furthermore, research on self-image and social images of older adults may enrich future studies in Japan and Sri Lanka.

2. This study provided adequate evidence for the continued belief in the extended family system as a foundation for family-based care in Sri Lanka, with a majority of students holding favorable views toward living in an extended family after their marriage. In contrast, Japanese students preferred living in nuclear families and visiting aging parents. Further, more male students indicated they would live with parents after their marriage than female students, demonstrating the influence of the cultural ethos in both countries.

3. The economic aspects of university students' perceptions were typical of young people from many Asian countries. Students in both countries had positive attitudes toward providing economic support to aging parents. However, there was a slight sex-based difference with more male students favoring the provision of economic support to aging parents than female students. Overall, students believed that family members (particularly children) should be responsible for the care of aging parents' daily life needs.

4. The tradition of children as the sole caregivers of bedridden parents persisted among a large proportion 
of students (about $60 \%$ in Japan and about $85 \%$ in Sri Lanka). In both countries, a similar number of students (40\%) indicated that children should take care of daily chores for aging parents and advocated social support. This could be interpreted as creating a dilemma in terms of families being unable to provide total care, or viewed as a belief that social support should meet new challenges. However, this is opposed to students' strong belief that institutional care should be avoided (about $47 \%$ in Japan, about $63 \%$ in Sri Lanka), and suggests that there are some uncertainties in students' attitudes toward family-based care giving with social support.

5. Care needs to be "age-friendly," as exemplified by participating students' opinions on the meaning of "being good to one's parents" when taking up responsibility for the care of older adults. This suggests policies that enhance the full participation of older adults are needed to support age-friendly measures. Our finding confirmed that students were indifferent to social support and should be considered important in terms of super-aged and aging societies by promoting engagement with older adults among university students.

6. This study indicates that Sri Lankan students are significantly less aware of active aging, and perceive older adults as being in poor physical and mental health and anxious about their health. Students expressed concern about elderly parents, and tended to be aware of the magnitude of the problem of population aging. Further, in both countries, female students were more interested in aging issues.

7. A significant proportion of students agreed there is age-based prejudice/discrimination in society. This study draws attention to the need for greater awareness about issues related to the care of older adults, and highlights the need for meaningful interventions on matters related to older adults and their families at the university level.

8. The evidence cited above underscores the importance of social perceptions, good communication, familiarity, and living/working together as vital in developing relationships with and consciousness about older adults. Regular/frequent communication with aging parents and providing care for them should be considered as enhancing dignity, promoting the rights of older adults, and improving consciousness/awareness among university students about supporting aging parents. This collaborative study is significant as it yielded encouraging results that may help change university students' perceptions about aging and promote positive intergenerational relationships. To achieve this, measures need to be implemented that allow university students to frequently interact with the older generation, while eschewing age-based discriminatory attitudes. This will help young adults learn about and view older adults more positively, which is important as older adults need to be in contact with younger generations to avoid being "out of sight and out of mind."

\section{Acknowledgements}

First, we wish to express our gratitude to the university students that freely agreed to complete the questionnaire; these students made the process of this research memorable. Our gratitude also goes to Tokai University, Japan, for funding which shaped this research. Furthermore, we extend sincere thanks to our colleagues at the National Institute of Social Development, Sri Lanka, and Tokai University, Japan. We are also grateful to the anonymous peer reviewers for their advice and Professor Bhavana Mehta, of the Faculty of Social Work, The Maharaja Sayajirao University of Aroda, India, and Dr. Venkat Pulla, Australian Catholic University for further suggestions and review. We thank Audrey Holmes (MA) from Edanz Group (www.edanzediting.com/ac) for editing a draft of this manuscript.

\section{REFERENCES}

Ministry of Internal Affairs and Communications, 2016, Online available from www.stat.go.jp/data/topics/pdf/topics97.pdf (Japan)

Institute for Health Metrics and Evaluation, Sri Lanka, 2015, Online available from http://www.healthdata.org/sri-lanka (Sri Lanka)

Economic and Social Affairs of the United Nations Secretariat, 2013.

W. I. D. Silva, Human Rights Commission of Sri Lanka, 2014: Growing old gracefully, Online available from http://www.hrcsl.lk/PFF/Growing_Old_Gracefully-Elders_Right s_Report.pdf

United Nations Population Division, Population Ageing Profile, United Nations, New York, 2013.

J. Prakash, Aging: Emerging Issues; CCR-IFCU Project on Aging and Development, Bangalore University, India, 2003.

M. Desai, S. Raju (Eds.), Gerontological Social Work in India: Some Issues and Perspectives, B. R. Publishing Cooperation, Delhi, 2000.

Cabinet Office, Government of Japan, Inquiry report about the ideas concerning age and aged society, 2003, Online available from

http://www8.cao.go.jp/kourei/ishiki/h15_kenkyu/gaiyou.html,ac cessed on 14.01.2016

UNFPA, Ageing Population in Sri Lanka; Issues and Future Prospects, Sri Lanka, 2004 
D. Somasundaram, S. Sivayokan, Mental Health in the Tamil Community, Shanthiham, Jaffna, Sri Lanka, 2005.

C. B. Bowen, V. Skirbek, National stereotypes of older people's competence are related to older adults' participation in paid and volunteer work, The Journals of Gerontology: Series B, Vol. 68, No. 6, 974-983, 2013. https://doi.org/10.1093/geronb/gbt101 accessed 29.06.2014

M. Lovell, Caring for the elderly: Changing perceptions and attitudes, Vascular Nursing, Vol. 24, No. 1, 22-26, 2006. http://www.ncbi.nlm.nih.gov/pubmed/22860477accessed29.06. 2014

L. C. Koh, Student attitudes and educational support in caring for older people: A review of literature, Nurse Education in Practice, Vol. 12, No. 1, 16-20, 2012. Accessed on 29.06.2014

J. Henderson, L. Xiao, M. Siegloff, J. Kelton, Paterson, Older people have lived their lives: first year nursing students' attitudes towards older people, Contemporary Nurse, Vol. 30, No.1, 32-45, 2008 .

K. Hosaka, T. Sodei, Images for the older people estimated by university students: Analysis by semantic differential method, Japan Journal of Social Gerontology, Vol. 27, 22-33, 1988.
Protection of the Rights of Elders Act, No 9 of 2000. Republic of Sri Lanka, 2000.

M. Kaplan, A. Kusano, I. Tsuji, S. Hisamichi, Intergenerational Programs Support for Children, Youth, and Elders in Japan, State University of New York Press, 1998.

H. Yokoyama, Supporting aging parents by their children-Changing consciousness for supporting their aging parents in recent years in Japan, In Gerontological Behavioral Association for the Aged and Aging Problems (Eds.), Encyclopedia of Behavioral Science Aspects for the Aged, pp.364-365, Chuo Hoki Publishing Co. Ltd., Japan, 2000.

M. W. Dhanapala, K. Yaguchi, A study on the social impact of changing family structure on the ageing people in Sri Lanka, Bulletin of School of Health Sciences in Tokai University, Vol. 21, 49-58, 2015.

A. Kusano, K. Watanabe, U. Uchida, M. Yasunaga, T. Yamanouchi (Eds.), The Theory and Practice of the Intergenerational Activities Between Children, Young Adults and Elderly People, Sangaku Publishing Co. Ltd., Japan, 2015 